\title{
Hepatocyte growth factor regulates the TGF-ß1-induced proliferation, differentiation and secretory function of cardiac fibroblasts
}

\author{
XIN YI, XIAOYAN LI, YANLI ZHOU, SHAN REN, WEIGUO WAN, GAOKE FENG and XUEJUN JIANG \\ Department of Cardiology, Renmin Hospital of Wuhan University and Cardiovascular Research Institute \\ of Wuhan University, Wuhan, Hubei 430060, P.R. China
}

Received January 11, 2014; Accepted May 9, 2014

DOI: $10.3892 /$ ijmm.2014.1782

\begin{abstract}
Cardiac fibroblast (CF) proliferation and transformation into myofibroblasts play important roles in cardiac fibrosis during pathological myocardial remodeling. In this study, we demonstrate that hepatocyte growth factor (HGF), an antifibrotic factor in the process of pulmonary, renal and liver fibrosis, is a negative regulator of cardiac fibroblast transformation in response to transforming growth factor- $\beta_{1}\left(\mathrm{TGF}-\beta_{1}\right)$. HGF expression levels were significantly reduced in the CFs following treatment with $5 \mathrm{ng} / \mathrm{ml} \mathrm{TGF}-\beta_{1}$ for $48 \mathrm{~h}$. The overexpression of HGF suppressed the proliferation, transformation and the secretory function of the CFs following treatment with TGF- $\beta_{1}$, as indicated by the attenuated expression levels of $\alpha$-smooth muscle actin ( $\alpha$-SMA) and collagen I and III, whereas the knockdown of HGF had the opposite effect. Mechanistically, we identified that the phosphorylation of c-Met, Akt and total protein of TGIF was significantly inhibited by the knockdown of HGF, but was significantly enhanced by HGF overexpression. Collectively, these results indicate that HGF activates the c-Met-Akt-TGIF signaling pathway, inhibiting CF proliferation and transformation in response to TGF- $\beta_{1}$ stimulation.
\end{abstract}

\section{Introduction}

Heart failure, one of the major causes of mortality in industrialized countries, is a global chronic non-communicable disease of the 21 st century (1). A recent study indicated that 5,800,000 Americans suffer from heart failure with a yearly incidence of 670,000 new cases and a yearly mortality rate of $>280,000$ individuals. Notably, more than one million

Correspondence to: Professor Xuejun Jiang, Department of Cardiology, Renmin Hospital of Wuhan University, Cardiovascular Research Institute, Wuhan University, 238 Jiefang Road, Wuhan, Hubei 430060, P.R. China

E-mail: xjjiang@whu.edu.cn

Key words: hepatocyte growth factor, cardiac fibroblasts, fibrosis, c-Met, Akt hospitalizations occur each year, while the treatment cost is approximately 40 billion dollars (2). Heart failure is often accompanied by the occurrence of cardiac fibrosis, which can be initiated by various pathological factors, including hypertension, myocardial infarction and cardiomyopathy (3-5). Cardiac fibrosis is characterized by the pathological accumulation of extracellular matrix (ECM) mainly consisting of collagen (6-8). In the heart, collagen is primarily secreted by cardiac fibroblasts (CFs) (9). CF proliferation and transformation into myofibroblasts under pathological conditions play a key role in the process of cardiac remodeling (10-16). CF transformation into myofibroblasts is primarily promoted by transforming growth factor- $\beta_{1}$ (TGF- $\left.\beta_{1}\right)$, cytokines, the ECM and other growth factors, which result in the excessive production of ECM and the expression or secretion of growth factors; in the long term, the CFs become maladaptive and lead to abnormal myocardial stiffness, and ultimately, cardiac dysfunction $(17,18)$. Therefore, the abrogation of CF transformation is one strategy for suppressing cardiac fibrotic remodeling that ultimately lead to heart failure.

Whereas many factors with a positive effect on CF activation have been described, relatively little is known about the factors that suppress the process of CF transformation (19-21). Of note, hepatocyte growth factor (HGF) is a potent antifibrotic cytokine that has been reported to have an antifibrotic function in various pathological conditions, such as pulmonary, liver and renal fibrosis (22-25). Previous studies have demonstrated that HGF inhibits $\alpha$-smooth muscle actin ( $\alpha$-SMA)-positive myofibroblast activation from resident $\mathrm{CFs}$ induced by TGF- $\beta_{1}$ or angiotensin II (26-28). These observations have led to the conclusion that HGF has great potential for negatively regulating $\mathrm{CF}$ function under pathological conditions, such as TGF- $\beta_{1}$ stimuli. It is known that HGF has multiple biological functions through its specific tyrosine kinase receptor, c-Met $(29,30)$. The binding of HGF to its receptor, an event that induces c-Met dimerization and activation, is then followed by the activation of multiple signaling pathways, such the ras-MAPK-ERK1/2, PI3K-Akt and TGF-Smad signaling pathways (31-33).

However, there is little information available as to how HGF affects the activation of CFs stimulated with TGF- $\beta_{1}$. Therefore, the aim of the present study was to investigate the 
specific effects of HGF on the function of cultured CFs and to explore the mechanisms of action of HGF in CFs in vitro. In addition, we wished to determine whether HGF binds to its receptor, c-Met, and induces c-Met activation, subsequently activating related signaling pathways, e.g., the MAPK-ERK1/2, PI3K-Akt and TGF-Smad2/3 pathways.

\section{Materials and methods}

Materials. Primary antibodies against the following proteins were purchased from Santa Cruz Biotechnology, Inc. (Santa Cruz, CA, USA): HGF (sc-13087); TGIF (sc-9084); Ki67 (sc-7846); von Willebrand Factor (vWF) (sc-27649); antibodies against vimentin (ab8978), $\alpha$-SMA (ab7817) were obtained from Abcam (Cambridge, MA, USA). Primary antibodies against MEK1/2 (no. 9122); ERK1/2 (no. 4695); phospho-

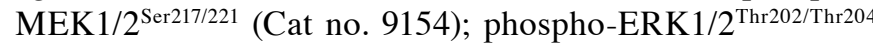
(no. 4370); phospho-Akt ${ }^{\mathrm{Th} 308}$ (no. 13038); Akt (no. 9272); phospho-c-Met ${ }^{\text {Tyr1003 }}$ (no. 3135); c-Met (no. 3127); phosphoSmad2 $2^{\operatorname{Ser} 465 / 467}$ (no. 3101); Smad2 (no. 5339); phosphoSmad3 $3^{\operatorname{Ser} 423 / 425}$ (no. 9520); Smad3 (no. 9523) and GAPDH (no. 2118) were from Cell Signaling Technology, Inc. (Beverly, MA, USA). Fetal bovine serum (FBS, no. SH30370.03) was purchased from HyClone (Logan, UT, USA). TRIzol was purchased from Invitrogen Life Technologies (Carlsbad, CA, USA) (no. 15596018). The BCA protein assay kit was purchased from Pierce Biotechnology, Inc. (Rockford, IL, USA) (no. 23235). Rat collagen I and III ELISA kits were obtained from NeoBioLab (Park Woburn, MA, USA) (no. RC0788 and no. RC0792). Cell culture reagents and all other reagents were purchased from Sigma (St. Louis, MO, USA).

Cultured neonatal rat CFs and adenovirus infection. Primary cultures of neonatal rat CFs were prepared from the ventricles of 1- to 2-day-old Sprague-Dawley (SD) rats using the differential attachment method, as previously described $(34,35)$. Briefly, the integrated hearts were removed and immediately placed in phosphate buffered saline (PBS), and the ventricles were minced, pooled, digested with $0.125 \%$ trypsin and $0.08 \%$ collagenase type II. The digestion was repeated 5 times. The collected cells were allowed to attach in DMEM/F12 medium supplemented with $10 \% \mathrm{FBS}$ and incubated at $95 \% \mathrm{O}_{2}+5 \% \mathrm{CO}_{2}$. After $1 \mathrm{~h}$ of attachment to the culture plates, the weakly attached or unattached cells were rinsed free and discarded, whereas the attached fibroblasts were grown in fresh DMEM/F12 supplemented with $10 \%$ FBS. Cells at passages 2-4 were used in the subsequent experiments. The identification of CFs was performed by immunofluorescence staining using anti-vWF for the detection of endothelial cells, anti-vimentin for fibroblasts and anti- $\alpha$-SMA for cardiomyocytes. CFs at $80 \%$ confluence in the culture wells were digested by $0.25 \%$ trypsin and then passaged at $1: 2$ dilutions. The cells were stimulated with TGF- $\beta_{1}$ with/without adenovirus transfection following starvation in serum-free DMEM/F12 for $12 \mathrm{~h}$. AdHGF, expressing rat HGF recombinant adenovirus, was generated by subcloning full-length rat HGF cDNA downstream of the cytomegalovirus (CMV) promoter into a replication-defective adenoviral vector. A similar adenoviral vector encoding the GFP gene (AdGFP) was used as a control. Three silencing rat shHGF constructs were obtained from SABiosciences (Frederick, MD, USA) (KR44869H).
Subsequently, AdshHGF adenoviruses were generated, and the construct that induced to the most significant decrease in HGF levels was selected for further experiments. AdshRNA was used as the control. The CFs were infected with recombinant adenoviruses at a multiplicity of infection (MOI) of 25 particles per cell for $24 \mathrm{~h}$.

Immunofluorescence staining. Immunofluorescence staining with the aforementioned antibodies was performed in the cultured CFs as previously described (36,37). Briefly, the CFs were washed 3 times with pre-cooling PBS, fixed with $4 \%$ paraformaldehyde and then permeabilized with $0.1 \%$ Triton X-100. Immunofluorescence staining was performed by incubating the CFs with vimentin, vWF, $\alpha$-SMA and Ki67 primary antibodies overnight at $4^{\circ} \mathrm{C}$. Following incubation with secondary antibodies for $60 \mathrm{~min}$ at room temperature, the CFs were incubated with DAPI for 10 min and mounted with aqueous mounting medium (Baso Diagnostics Inc., Taipei, Taiwan. Finally, the stained cells were visualized under a fluorescence microscope (Olympus Corp, Tokyo, Japan).

Cell proliferation assay. Cell proliferation was assessed by cell counting kit-8 (CCK8) assay according to the manufacturer's instructions. The cell suspension of CFs was inoculated into each 96-well plate at a density of $1 \times 10^{4}$ cells $/ \mathrm{ml}$. After the CFs were treated with TGF- $\beta_{1}$ with/without adenovirus infection, $10 \mu 1$ of CCK8 solution were added to each well. The absorbance (A450) was measured to evaluate cell numbers and then estimate cell proliferation.

Real-time polymerase chain reaction (PCR) analysis. Total RNA was extracted from the cells using TRIzol reagent according to the manufacturer's instructions and the cDNA was synthesized using oligo(dT) primers with the transcriptor first-strand cDNA synthesis kit. Selected gene differences were confirmed by real-time PCR using SYBR-Green and the results were normalized against GAPDH gene expression. The sequences of all primers used in this study are presented in Table I.

Western blot analysis. Total protein was extracted from the cultured CFs as previously described $(38,39)$. Briefly, the lysates were collected by centrifugation at $10,000 \mathrm{x} \mathrm{g}$. The protein concentrations were determined using a BCA protein assay kit. Fifty micrograms of protein extract were used for SDS-PAGE. The proteins were then transferred onto nitrocellulose membranes, blocked with 5\% skimmed milk powder and then probed with various antibodies overnight at $4^{\circ} \mathrm{C}$. Following incubation with a secondary peroxidase-conjugated antibody (Jackson ImmunoResearch Laboratories, Inc., West Grove, PA, USA; at a 1:10,000 dilution), signals were visualized with FluorChem E (Cell Biosciences, Santa Clara, CA, USA). Specific protein expression levels were normalized to GAPDH for total cell lysates and cytosolic proteins on the same nitrocellulose membrane.

Enzyme-linked immunosorbent assay (ELISA). Collagen I and III levels in the CF culture supernatant were measured using the the rat ELISA kits according to the manufacturer's instructions. In brief, the culture supernatant was added to each 
Table I. Primer pair sequences used for the real-time PCR analysis of gene expression.

\begin{tabular}{lll}
\hline Gene & \multicolumn{1}{c}{ Forward } & \multicolumn{1}{c}{ Reverse } \\
\hline GAPDH & GGGTGATGCTGGTGCTGAGTATGT & CAGTGGATGCAGGGATGATGTTCT \\
PCNA & CAACTTGGAATCCCAGAACAGGAG & TAAGGTCCCGGCATATACGTGC \\
Ki67 & TAGAGGATCTGCCTGGCTTC & TGTCCTTGGTTGGTTCCTCC \\
$\alpha-S M A$ & GCTCTGTAAGGCGGGCTTTG & ACGAAGGAATAGCCACGCTCA \\
Cyclin D1 & GAACTACCTGGACCGTTTCTTG & AGGAAGTGTTCGATGAAATCGT \\
Collagen I & GAGCGGAGAGTACTGGATCGA & CTGACCTGTCTCCATGTTGCA \\
Collagen III & TGCCATTGCTGGAGTTGGA & GAAGACATGATCTCCTCAGTGTTGA \\
HGF & ATCAGACACCACACCGGCACAAAT & GAAATAGGGCAATAATCCCAAGGAA \\
\hline
\end{tabular}

PCR, polymerase chain reaction; PCNA, proliferating cell nuclear antigen; $\alpha$-SMA, $\alpha$-smooth muscle actin; HGF, hepatocyte growth factor.

A

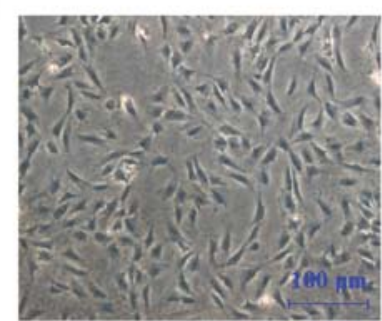

B

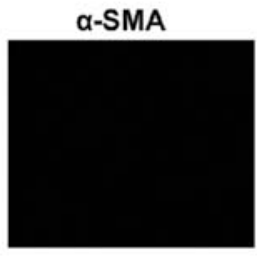

C

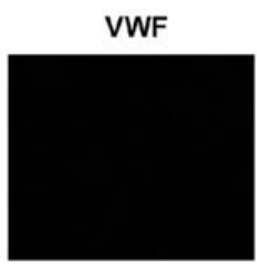

D

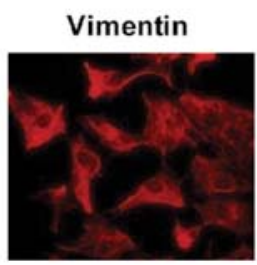

DAPI

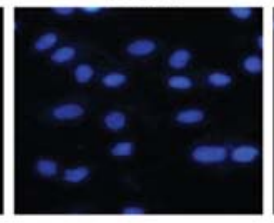

DAPI

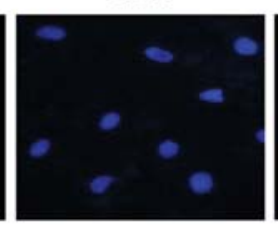

DAPI

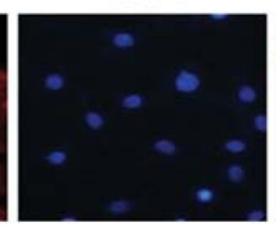

Merge
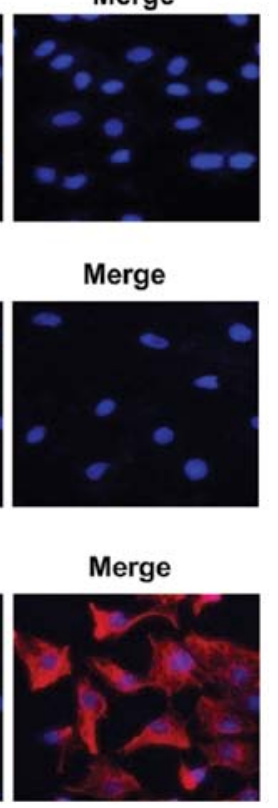

Figure 1. Characterization of primary cultured neonatal rat cardiac fibroblasts (CFs). (A) Cell morphology of first passage of neonatal rat CFs under an optical microscope (scale bar, $100 \mu \mathrm{m}$ ). (B-D) Primary cultured cardiac fibroblasts were subjected to immunofluorescence staining for (B) $\alpha$-smooth muscle actin ( $\alpha$-SMA); (C) von Willebrand factor (vWF); and (D) vimentin to identify their purity [red, $\alpha$-SMA/vWF/Vimentin staining; DAPI, blue (nuclear)]. Three independent experiments were performed.

ELISA plate well pre-coated with anti-rat collagen I and III polyclonal antibodies. Following $1 \mathrm{~h}$ of incubation at room temperature, the plates were washed and rat collagen I and III conjugate was then added to each well. The plates were incubated at room temperature for $2 \mathrm{~h}$. The plates were then

washed again, and substrate solution was added to each well. The plates were then incubated at room temperature in the dark for color development. After $30 \mathrm{~min}$, stop solution was added to each well. The absorbance in each well was measured at $550 \mathrm{~nm}$ using a microplate reader. The concentrations of collagen I and III in the samples were determined by interpolation from the standard curve.

Statistical analysis. The data are expressed as the means \pm standard deviation (SD). Differences between various groups were tested with one-way ANOVA followed by the least significant difference (LSD) t-test using SPSS 13.0 statistical software. Comparisons between 2 groups were performed by an unpaired Student's t-test. A value of $\mathrm{P}<0.05$ was considered to indicate a statistically significant difference.

\section{Results}

Characterization of primary cultured neonatal rat CFs. The first passage of neonatal rat CFs cultured in our study had the typical morphological characteristics of fibroblasts, as evidenced by the spindle or polygonal shape of the cells, or the irregularly branched cytoplasm with a large ovoid nucleus (Fig. 1A) (40). The results of immunofluorescence staining revealed that these cells were negative for $\alpha$-SMA and VWF, which are the markers of cardiomyocytes and endothelial cells, respectively (Fig. 1B and C) $(41,42)$, but positive for vimentin, a marker of fibroblasts (Fig. 1D) (43). All these characteristics indicated that these cultured cells were CFs.

HGF expression levels are decreased in CFs stimulated with TGF- $\beta_{1}$. To investigate the appropriate concentration and stimulation time of TGF- $\beta_{1}$ in inducing CF transformation into myofibroblasts, we first measured the effects of several concentrations of TGF- $\beta_{1}$ on inducing $\alpha$-SMA protein expression after $48 \mathrm{~h}$ of incubation, which is the hallmark of myofibroblasts (44-46). It was found that the induction of $\alpha$-SMA expression was highest when TGF- $\beta_{1}$ was added at a concentration of $5 \mathrm{ng} / \mathrm{ml}$ (Fig. $2 \mathrm{~A}$ and $\mathrm{B}$ ). In addition, it was found that TGF- $\beta_{1}$ induced $\alpha$-SMA expression in the cultured CFs in a time-dependent manner. Compared with 12 and $24 \mathrm{~h}$ of incubation, the maximal expression of $\alpha$-SMA protein was found at 48 and $72 \mathrm{~h}$ following stimulation with 
A

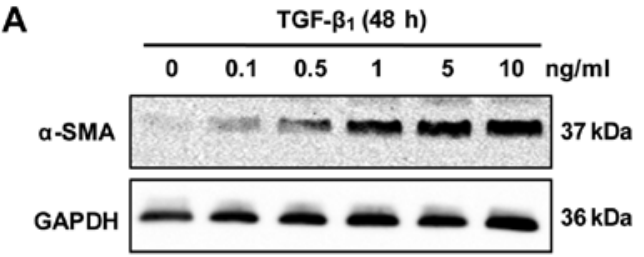

C

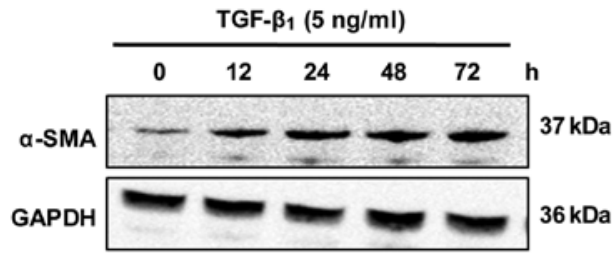

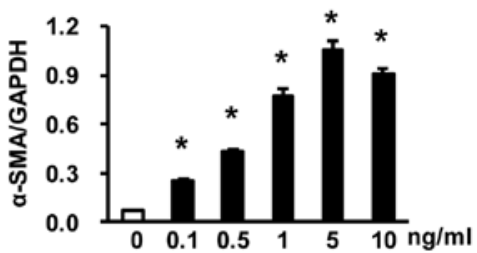

D

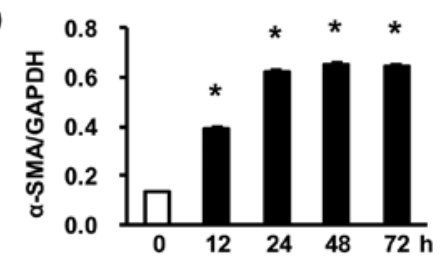

E

$\mathbf{F}$
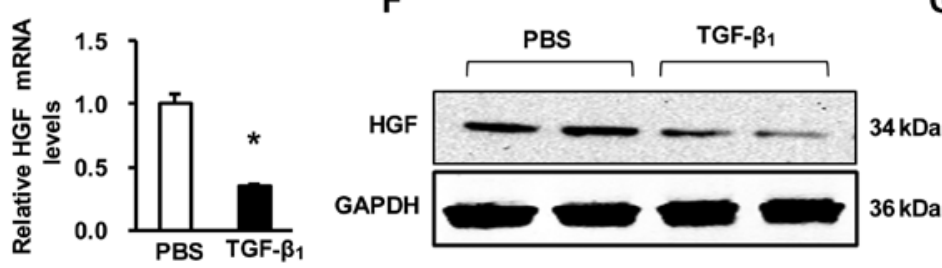

G

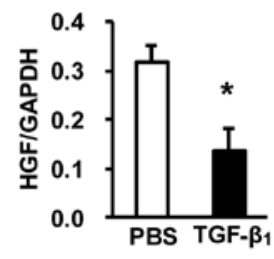

Figure 2. Hepatocyte growth factor (HGF) expression levels are decreased in cardiac fibroblasts (CFs) treated with transforming growth factor- $\beta_{1}\left(\mathrm{TGF}-\beta_{1}\right)$. (A and B) The protein levels of $\alpha$-SMA in primary cultured CFs treated with $0,0.1,0.5,1,5$ and $10 \mathrm{ng} / \mathrm{ml}$ TGF- $\beta_{1}$ for $48 \mathrm{~h}$; (A) representative western blots; (B) quantitative results. "P<0.05 vs. $0 \mathrm{ng} / \mathrm{ml}$. (C and D) Protein levels of $\alpha$-SMA in the samples from primary cultured CFs treated with $5 \mathrm{ng} / \mathrm{ml}$ TGF- $\beta_{1}$ for 0 , $12,24,48$ and $72 \mathrm{~h}$; (C) representative western blots; (D) quantitative results. "P<0.05 vs. $0 \mathrm{~h}$. (E) Relative mRNA levels of HGF in CFs following treatment with $5 \mathrm{ng} / \mathrm{ml}$ TGF- $\beta_{1}$ for $48 \mathrm{~h}$. "P<0.05 vs. phosphate-buffered saline (PBS). (F and G) Protein levels of HGF in the samples from primary cultured CFs stimulated with $5 \mathrm{ng} / \mathrm{ml}$ TGF- $\beta_{1}$ for $48 \mathrm{~h}$; (F) representative western blots; (G) quantitative results. " $\mathrm{P}<0.05$ vs. PBS. Three independent experiments were performed.

$5 \mathrm{ng} / \mathrm{ml} \mathrm{TGF}-\beta_{1}$ (Fig. 2C and D) Therefore, we selected $5 \mathrm{ng} /$ $\mathrm{ml}$ TGF- $\beta_{1}$ with $48 \mathrm{~h}$ of incubation to induce CF transformation into myofibroblasts. To investigate the role of HGF in the function of CFs, we first measured HGF expression in the CFs that were stimulated with PBS or $5 \mathrm{ng} / \mathrm{ml}$ TGF- $\beta_{1}$. Real-time PCR revealed that, compared with the PBS control, the mRNA levels of HGF were significantly downregulated in the fibroblasts stimulated with TGF- $\beta_{1}$ for $48 \mathrm{~h}$ (Fig. 2E). This result was confirmed by western blot analysis, which showed that the HGF protein levels were reduced following treatment with $5 \mathrm{ng} / \mathrm{ml}$ TGF- $\beta_{1}$ for $48 \mathrm{~h}$ (Fig. $2 \mathrm{~F}$ and G). These results indicate that HGF may play a role in the function of CFs.

Knockdown of HGF enhances the proliferation, transformation and secretory function of CFs. To define the functional contribution of HGF to the proliferation and transformation of $\mathrm{CFs}$ in vitro, the second passage of cultured neonatal rat $\mathrm{CFs}$ was infected with AdshHGF in order to knockdown HGF. As shown in Fig. 3A and B, the HGF protein levels were significantly reduced in the CFs infected with AdshHGF. Compared with the control (AdshRNA-infected), the CFs infected with AdshHGF presented an enhanced proliferation (Fig. 3C and D). Cell proliferation assay and the immunostaining of Ki67 revealed that TGF- $\beta_{1}$ markedly enhanced the proliferation of the CFs compared with the PBS group, but this effect was further enhanced in the CFs in which HGF was knocked down (Fig. 3C and D). Additionally, we performed real-time PCR to determine the mRNA levels of proliferating cell nuclear antigen (PCNA), Ki67 and cyclin D1 in the CFs infected with AdshHGF/AdshRNA. The results revealed that, compared with the AdshRNA group, the mRNA levels of PCNA, Ki67 and cyclin D1 were markedly increased in the AdshHGF-infected CFs following stimulation with TGF- $\beta_{1}$ (Fig. 3E). Under the appropriate conditions, resting or quiescent CFs can transform into myofibroblasts, which possess a more active, synthetic and contractile phenotype $(47,48)$. We therefore determined whether HGF affects the phenotype switching of CFs following treatment with TGF- $\beta_{1}$. The $\alpha$-SMA levels in the CFs were determined by immunofluorescence and real-time PCR (Fig. 3F and G). Compared to the AdshRNA control group, the TGF- $\beta_{1}-$ induced expression of $\alpha$-SMA was markedly increased by HGF knockdown (AdshHGF) (Fig. 3F and G). A number of studies have shown that, under inappropriate conditions, CFs may secrete fibrosis-related factors, such as collagen I and III, to promote the development of fibrosis (49-51). The results of ELISA showed that the collagen I and III levels were increased in the culture medium; this indicated that the AdshHGFinfected $\mathrm{CFs}$ had an enhanced secretory function (Fig. 3H). Moreover, the results of real-time PCR were consistent with the results of ELISA (Fig. 3I). Collectively, these loss-of-function data indicate that the knockdown of HGF enhances the proliferation, transformation and secretory function of $\mathrm{CFs}$.

Overexpression of HGF attenuates the TGF- $\beta_{1}$-induced proliferation, transformation and secretory function of $C F$ s. We then sought to examine whether increasing HGF levels in the CFs would attenuate their proliferation, transformation and secretory function. Thus, we overexpressed HGF in the second passage of cultured neonatal rat CFs by infection with AdHGF. The HGF protein levels markedly increased $(\sim 2.3$-fold $)$ in the 
A

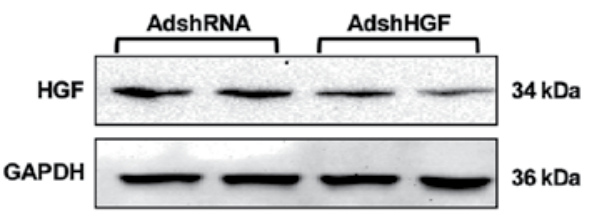

B

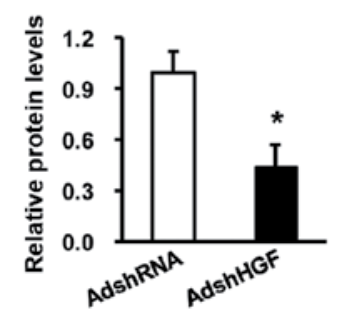

C

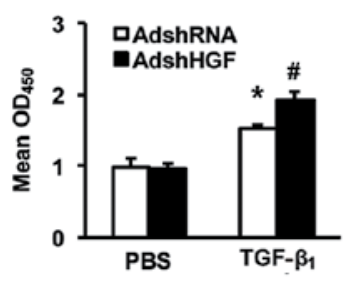

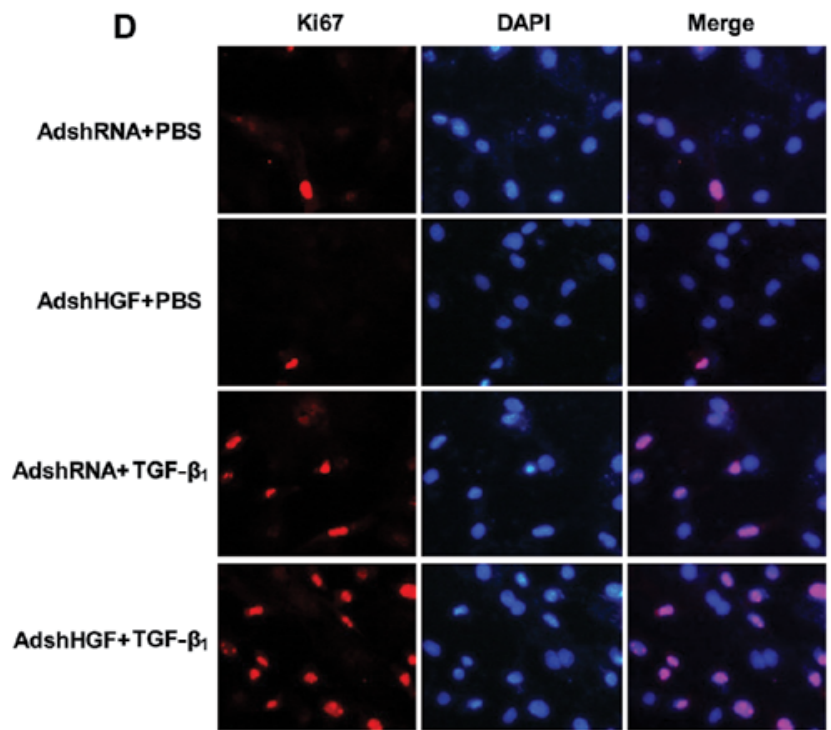

$\mathbf{F}$

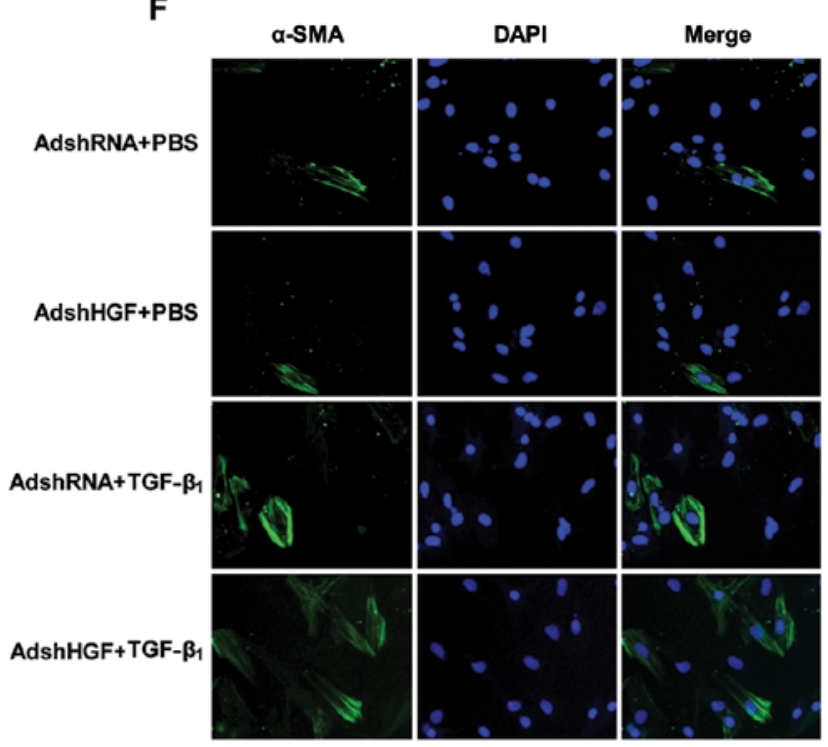

$\mathbf{E}$

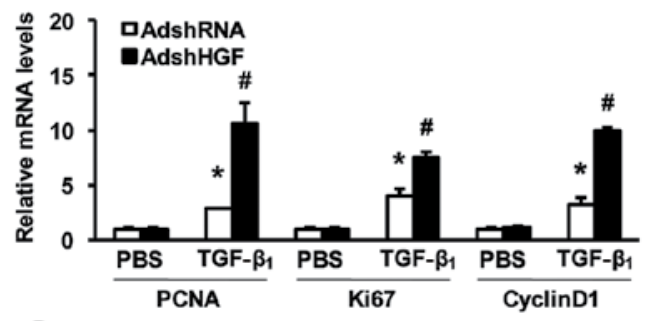

G

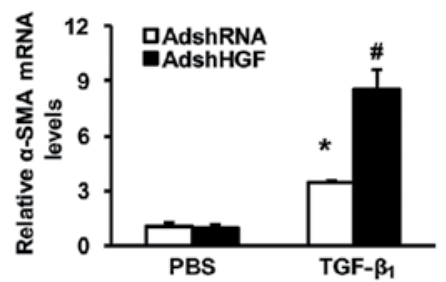

H
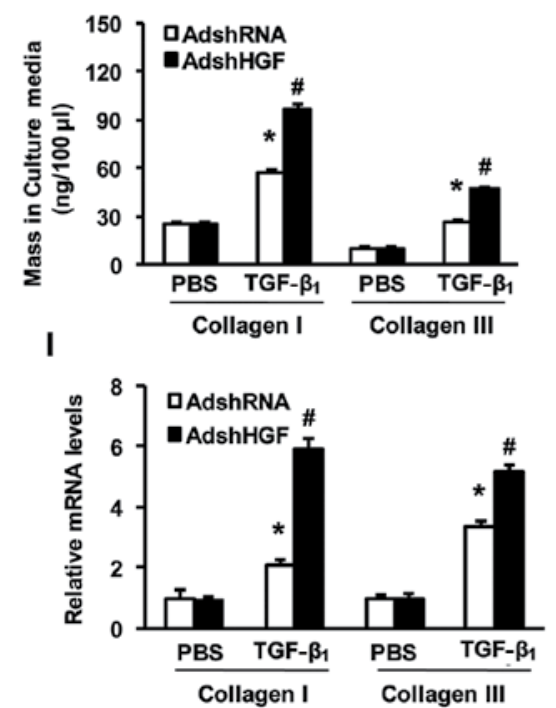

Figure 3. Knockdown of hepatocyte growth factor (HGF) in cardiac fibroblasts (CFs) enhances proliferation, transformation and secretory function. (A and B) HGF protein levels in CFs infected with AdshRNA or AdshHGF; (A) representative western blots; (B) quantitative results. "P<0.05 vs. AdshRNA. (C) CCK8 assays were performed to measure the proliferation of CFs infected with AdshRNA or AdshHGF following stimulation with $5 \mathrm{ng} / \mathrm{ml}$ transforming growth factor- $\beta_{1}$ (TGF- $\beta_{1}$ ) for 48 h. (D) The immunostaining results showed that Ki67 expression levels was increased in AdshHGF infected CFs following stimulatin with $5 \mathrm{ng} / \mathrm{ml}$ TGF- $\beta_{1}$ for $48 \mathrm{~h}$ compared with AdshRNA control (red, Ki67; blue, nuclear). (E) Relative mRNA levels of PCNA, Ki67 and cyclin D1 in samples from CFs of the indicated groups. (F) The $\alpha$-SMA immunostaining in CFs of the indicated groups. [green, $\alpha$-smooth muscle actin ( $\alpha$-SMA); blue, nuclear]. (G) Relative mRNA levels of $\alpha$-SMA in CFs of the indicated groups. (H) Collagen I and III protein secretion in the culture medium of the indicated groups determined by enzyme-linked immunosorbent assay (ELISA). (I) Relative mRNA levels of collagen I and III in the CFs of the indicated groups. ${ }^{*} \mathrm{P}<0.05$ vs. AdshRNA/phosphate-buffered saline (PBS); ${ }^{"} \mathrm{P}<0.05$ vs. AdshRNA/TGF- $\beta_{1}$. Three independent experiments were performed.

CFs infected with AdHGF (Fig 4A and B). CF proliferation was then determined by CCK8 assay, and immunostaining of Ki67 and PCNA, Ki67 and cyclin D1 mRNA. Notably, AdHGF did not affect the proliferation of the CFs compared with the control AdGFP-infected cells treated with PBS. However, when the CFs were exposed to $5 \mathrm{ng} / \mathrm{ml}$ TGF- $\beta_{1}$, the proliferation of the CFs was markedly inhibited by the overexpression of HGF compared with AdGFP (Fig. 4C-E). We also assessed the 
A

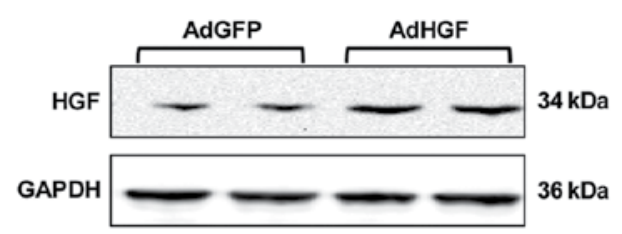

B

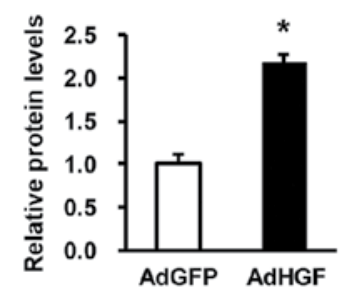

C

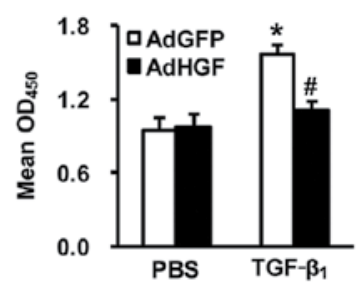

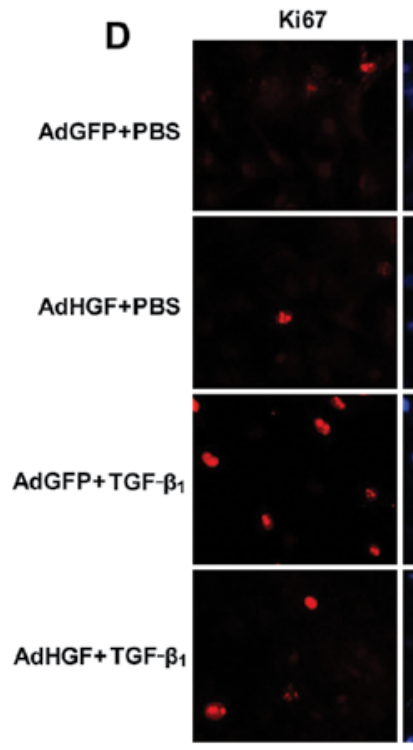

$\mathbf{F}$

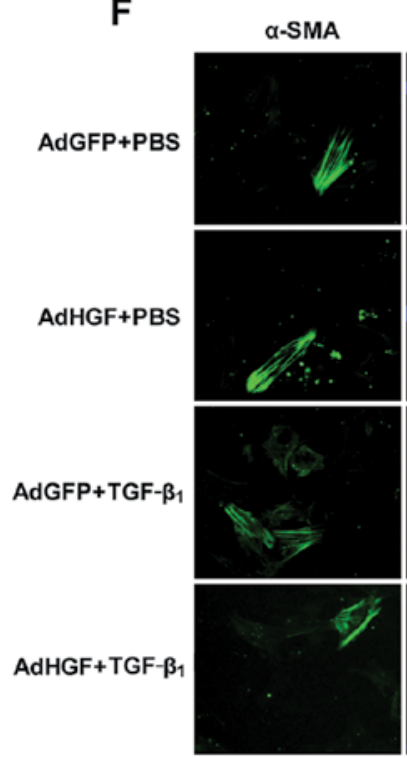

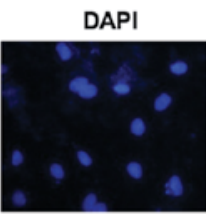
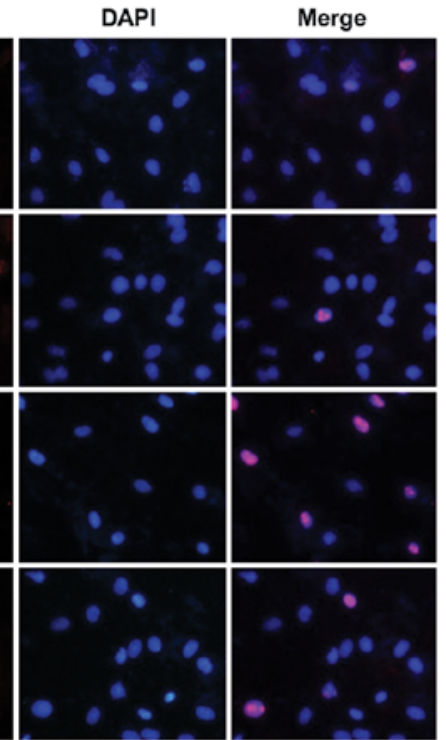

DAPI

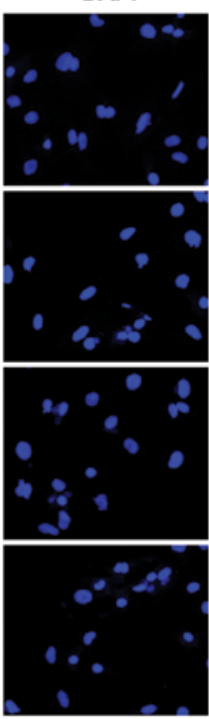

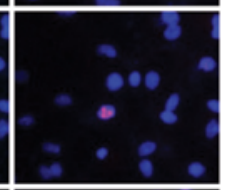

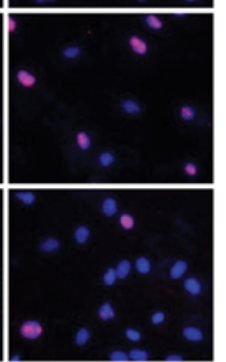

Merge

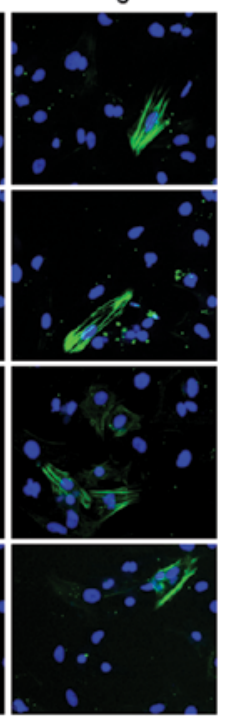

E
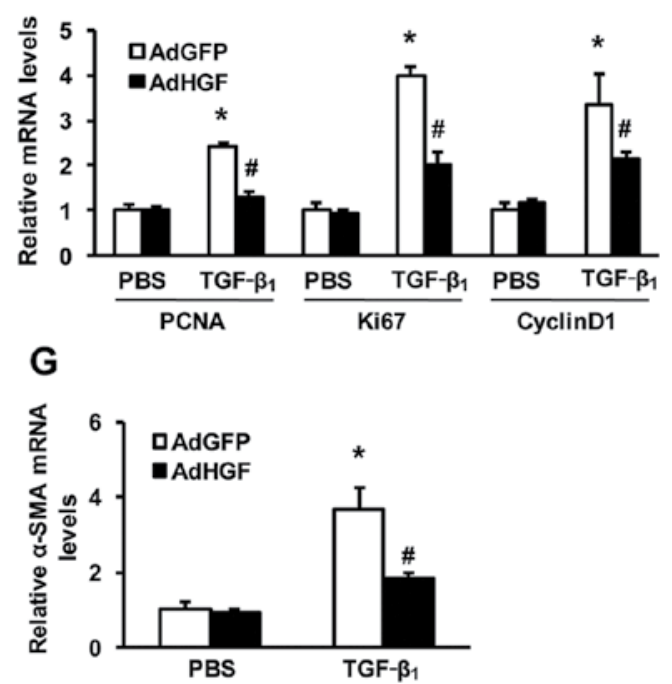

$\mathrm{H}$
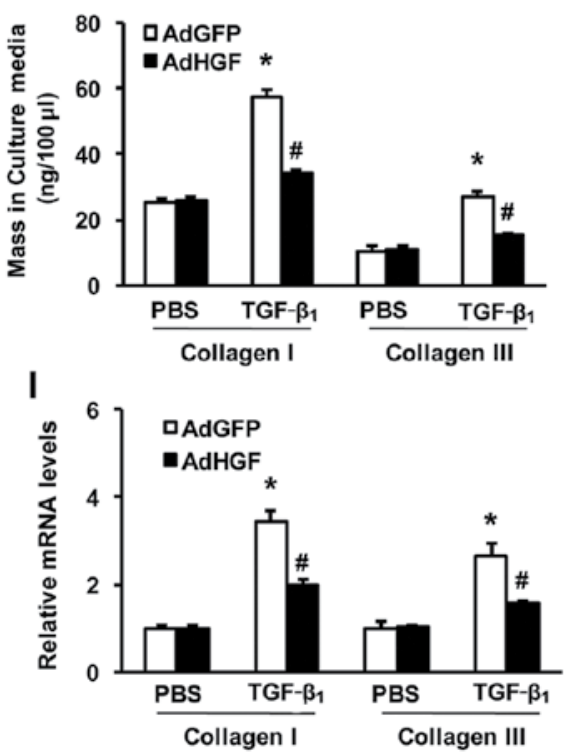

Figure 4. Overexpression of hepatocyte growth factor (HGF) in cardiac fibroblasts (CFs) attenuates transforming growth factor- $\beta_{1}$ (TGF- $\left.\beta_{1}\right)$-induced proliferation, transformation and secretory function. (A and B) HGF protein levels in CFs infected with AdGFP or AdHGF; (A) representative western blots; (B) quantitative results. ${ }^{*} \mathrm{P}<0.05$ vs. AdGFP. (C) The CCK8 assays results indicated that the proliferation of CFs was suppressed by infection with AdHGF following stimulation with $5 \mathrm{ng} / \mathrm{ml} \mathrm{TGF}-\beta_{1}$ for $48 \mathrm{~h}$. (D) Repesentative images from immunofluorescence staining of Ki67 in CFs infected with AdGFP or AdHGF and stimulated with $5 \mathrm{ng} / \mathrm{ml} \mathrm{TGF}-\beta_{1}$ for $48 \mathrm{~h}$ (red, Ki67; blue, nuclear). (E) The relative mRNA levels of PCNA, Ki67, and cyclin D1 in samples from CFs of the indicated groups. (F) Repesentative images from immunofluorescence staining of $\alpha$-smooth muscle actin $(\alpha-S M A)$ in CFs infected with AdGFP or AdHGF and stimulated with $5 \mathrm{ng} / \mathrm{ml}$ TGF- $\beta_{1}$ for $48 \mathrm{~h}$ (green, $\alpha$-SMA; blue, nuclear). (G) Relative mRNA levels of $\alpha$-SMA in CFs of the indicated groups. (H) Collagen I and III protein secretion in the culture medium of the indicated groups determined by ELISA. (I) Relative mRNA levels of collagen I and III in the CFs of the indicated groups. ${ }^{*} \mathrm{P}<0.05$ vs. AdGFP/phosphate-buffered saline (PBS); ${ }^{\#} \mathrm{P}<0.05$ vs. AdGFP/ TGF- $\beta_{1}$. Three independent experiments were performed.

effects of HGF overexpression on the TGF- $\beta_{1}$-induced transformation of CFs. The results of immunostaining and real-time PCR consistently showed that the $\alpha$-SMA levels in the CFs were markedly reduced following stimulation with TGF- $\beta_{1}$ compared with the AdGFP control (Fig. 4F and G). Moreover, ELISA was used to evaluate the levels of collagen I and III in the 
A
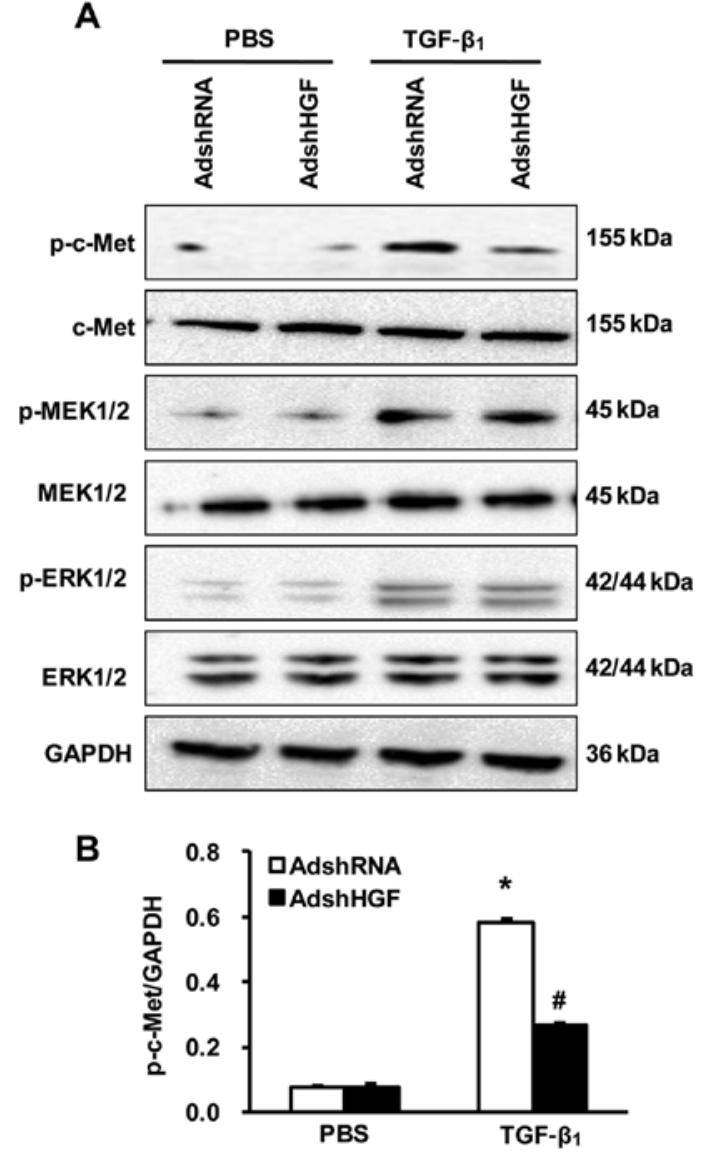

C

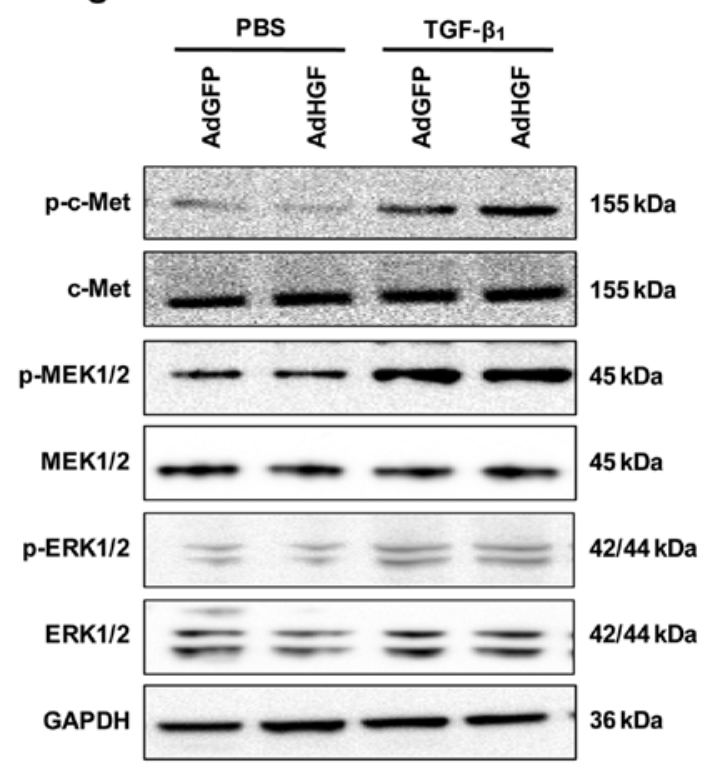

D

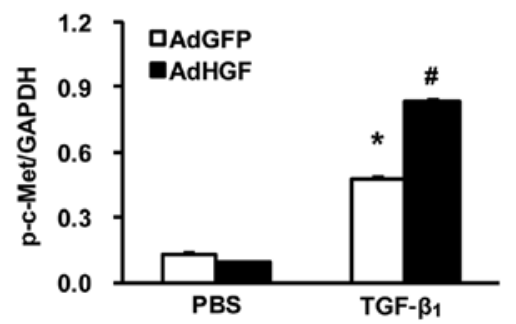

Figure 5. Effects of hepatocyte growth factor (HGF) on c-Met-MEK-ERK signaling. (A and B) Phosphorylation and total protein levels of c-Met, MEK1/2,ERK1/2 in AdshRNA- or AdshHGF-infected cardiac fibroblasts (CFs) stimulated with $5 \mathrm{ng} / \mathrm{ml}$ transforming growth factor- $\beta_{1}$ (TGF- $\beta_{1}$ ) for $48 \mathrm{~h}$. (A) Representative western blots; (B) Quantitative results. (C and D) Phosphorylation and total protein levels of c-Met, MEK1/2 and ERK1/2 in samples from AdGFP- or AdHGFinfected CFs stimulated with $5 \mathrm{ng} / \mathrm{ml}$ TGF- $\beta_{1}$ for $48 \mathrm{~h}$. (C) Representative western blots; (D) quantitative results. Three independent experiments were performed. ${ }^{*} \mathrm{P}<0.05$ vs. AdshRNA or AdGFP/phosphate-buffered saline (PBS); ${ }^{\mathrm{P}}<0.05$ vs. AdshRNA or AdGFP/ TGF- $\beta_{1}$.

culture medium. The results indicated that the secretory function of the CFs was markedly inhibited by the overexpression of HGF following treatment with TGF- $\beta_{1}$ (Fig. 4H); this was consistent with the results obtained by real-time PCR (Fig. 4I). Taken together, these data suggest that the overexpression of HGF suppresses the proliferation, transformation and secretory function of CFs.

HGF activates c-Met-Akt-TGIF signaling, inhibiting the function of CFs. As is known, HGF is the ligand of c-Met, and its phosphorylation activates downstream signaling (31-33). Thus, we first determined whether HGF affects the phosphorylation of c-Met following TGF- $\beta_{1}$ stimulation. Western blot analysis with specific antibody to phospho-c-Met showed that the phosphorylation of c-Met was inhibited by the knockdown of HGF (AdshHGF), but was significantly enhanced by HGF overexpression (AdHGF) following TGF- $\beta_{1}$ stimulation (Fig. 5). However, the phosphorylation of MEK $1 / 2$ and ERK1/2, downstream of c-Met, was not altered after the knockdown or the overexpression of HGF in the CFs stimulated with TGF- $\beta_{1}$ (Fig. 5). These results indicate that HGF may not suppress the effects of TGF- $\beta_{1}$ on CFs through the classic signaling pathway, MAPK-ERK1/2.

In order to gain insight into the molecular mechanisms underlying the negative role of HGF in the function of CFs we observed in vitro, we investigated whether the phosphorylation of Smad2 and Smad3 is enhanced in Cfs infected with AdshRNA and AdGFP following stimulation with TGF- $\beta_{1}$. We found that there was no difference between the CFs infected with AdshRNA/AdshHGF or the CFs infected with AdGFP/AdHGF following treatment with TGF- $\beta_{1}$ (Fig. 6A and B). Notably, the phosphorylation of Akt and total protein of TGIF (a Smad transcriptional co-repressor) was significantly suppressed in the CFs in which HGF was knocked down, but increased in the CFs in which HGF was overexpressed following TGF- $\beta_{1}$ stimulation (Fig. 6C-F). Collectively, these data indicate that HGF positively regulates the c-Met-Akt-TGIF signaling pathway, inhibiting the function of CFs in response to TGF- $\beta_{1}$ stimuli.

\section{Discussion}

In the present study, we investigated the effects of HGF on the response of cultured CFs, as well as the possible mechanisms of involved. CFs were important in the cardiac remodeling process. We demonstrated that: i) TGF- $\beta_{1}$ induced $\alpha$-SMA expression in the cultured CFs in a time- and concentration-dependent manner; the maximal expression of $\alpha$-SMA protein was investigated in the CFs treated with $5 \mathrm{ng} / \mathrm{ml} \mathrm{TGF}-\beta_{1}$ for $48 \mathrm{~h}$; ii) HGF inhibited the proliferation of CFs; iii) HGF inhibited the differentiation 

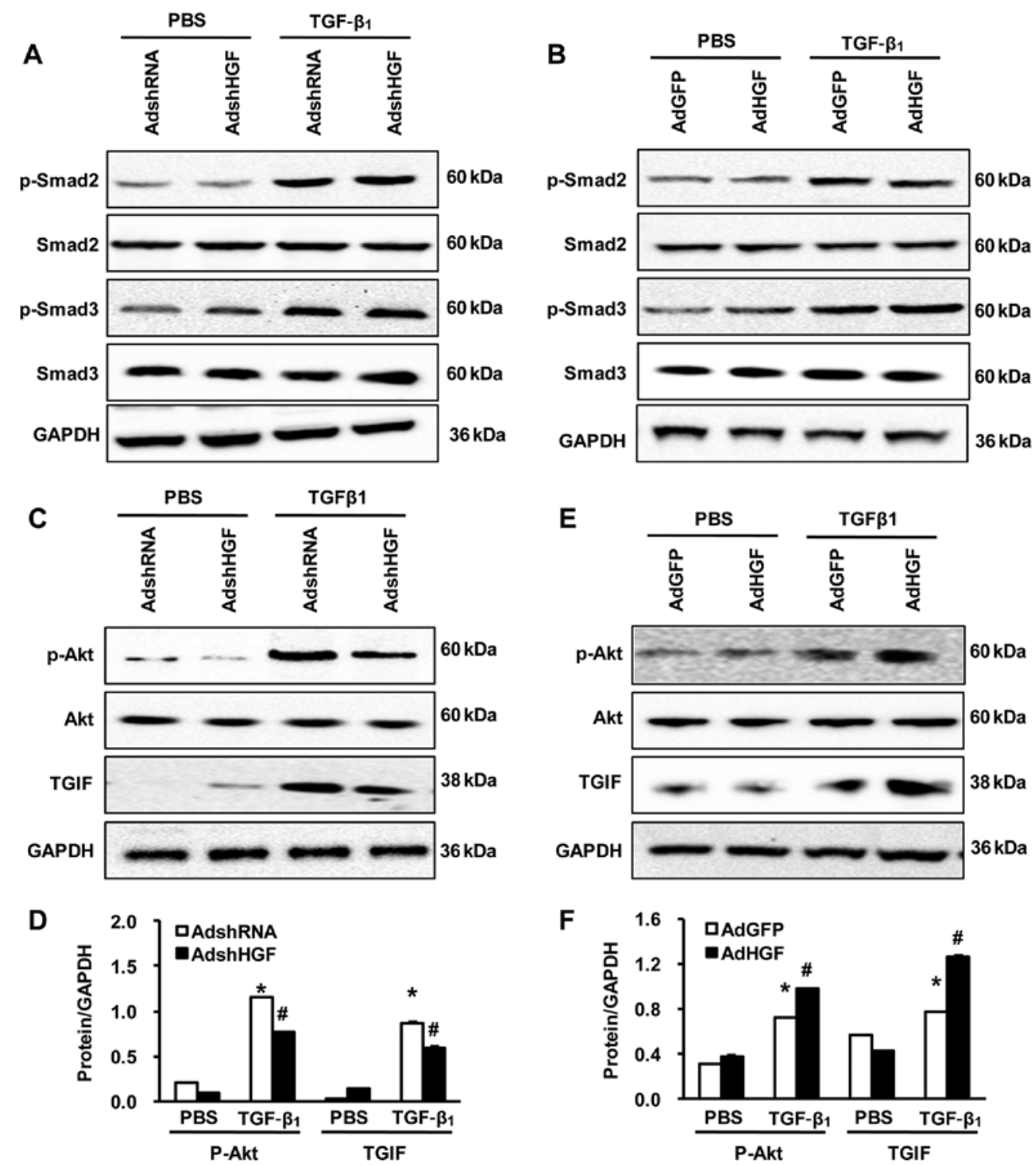

Figure 6. Effects of hepatocyte growth factor (HGF) on Akt-TGIF signaling. (A) Representative western blots showing the phosphorylation and total protein levels of Smad2 and Smad3 in AdshRNA or AdshHGF or (B) in AdGFP- or AdHGF-infected cardiac fibroblasts (CFs) stimulated with $5 \mathrm{ng} / \mathrm{ml}$ TGF- $\beta_{1}$ for $48 \mathrm{~h}$. (C-F) Phosphorylation and total protein levels of Akt and total protein of TGIF in AdshRNA- or AdshHGF-infected CFs stimulated with $5 \mathrm{ng} / \mathrm{ml}$ transforming growth factor- $\beta_{1}$ (TGF- $\beta_{1}$ ) for $48 \mathrm{~h}$. (C and E) Representative western blots; (D and F) quantitative results. Three independent experiments were performed. ${ }^{*} \mathrm{P}<0.05$ vs. AdshRNA or AdGFP/phosphate-buffered saline (PBS); ${ }^{\mathrm{P}}<0.05$ vs. AdshRNA or AdGFP/TGF- $\beta_{1}$.

of CFs into myofibroblasts; iv) HGF decreased the synthesis and secretion of collagen I and III in the CFs; v) HGF activated the phosphorylation of its receptor, c-Met; vi) TGF- $\beta_{1}$ stimulation increased the phosphorylation of MEK1/2 and ERK1/2, downstream of c-Met, but the knockdown or the overexpression of HGF did not alter the phosphorylation levels of the aforementioned signaling molecules; vii) the phosphorylation of Smad 2 and Smad3 was enhanced in the CFs following stimulation with TGF- $\beta_{1}$, but there was no difference between HGF knockdown and HGF overexpression; viii) the phosphorylation of Akt and total protein of TGIF were significantly suppressed in the CFs in which HGF was knocked down, but increased in the CFs in which HGF was overexpressed following TGF- $\beta_{1}$ stimulation.

CFs represent the largest class of cells residing in the normal heart, and the proliferation of CFs is the main characteristic of cardiac fibrosis $(52,53)$. In the present study, by CCK8 assay, we investigated whether HGF inhibits $\mathrm{CF}$ proliferation, as indicated by the decreased mRNA levels of CF proliferation markers, such as Ki67, PCAN and cyclin D1. Hence, HGF is effective for the treatment of cardiac fibrosis. The phenotypic transformation of CFs into myofibroblasts is known to be another key event in the process of cardiac remodeling. Under abnormal conditions, the persistence of myofibroblasts can facilitate hypertrophy and fibrosis, which results in structural remodeling and cardiac dysfunction $(54,55)$. Therefore, the prevention of myofibroblast transformation may be a potential therapy aiming at limiting cardiac fibrosis. Cardiac myofibroblasts are greatly active cells that express $\alpha$-SMA and exhibit increased synthesis and secretion of massive collagen proteins, such as collagen I and III (56-58). In this study, we demonstrated that HGF significantly attenuated the $\alpha$-SMA and collagen I 
and III expression levels in the CFs. The present study using cultured CFs confirmed the beneficial effects of HGF shown in animal models (59-61). However, the most impressive finding of the present study was that HGF positively inhibited the function of $\mathrm{CFs}$ in response to TGF- $\beta_{1}$ stimuli by regulating the c-Met-Akt-TGIF signaling. As is known, HGF is the ligand of c-Met, and its phosphorylation activates downstream signaling (31-33). Thus, we first determined that the phosphorylation of c-Met was inhibited by the knockdown of HGF, but was significantly enhanced by HGF overexpression following TGF- $\beta_{1}$ stimulation. Furthermore, the downstream signaling of c-Met and the phosphorylation of Akt were significantly suppressed follwoing HGF knockdown, but increased following HGF overexpression. However, the phosphorylation of MEK1/2 and ERK1/2, classic downstream signaling molecules of c-Met, was not altered after the knockdown or overexpression of HGF in the CFs stimulated with TGF- $\beta_{1}$, indicating that HGF may not restrain the function of TGF- $\beta_{1}$ on CFs through the classic MAPK-ERK1/2 signaling pathway.

Smad proteins are thought to play an important role in regulating intracellular responses to TGF- $\beta_{1}$. Smad proteins, such as Smad 2 and Smad3, are activated by TGF- $\beta_{1}$ receptors and then translocate to the nucleus, where they regulate transcription, further modifying multipleCFfunctions, including proliferation, differentiation and secretion. Indeed, our study demonstrated that TGF- $\beta_{1}$ induced Smad2 and Smad phosphorylation in the CFs. However, HGF failed to attenuate TGF- $\beta_{1}$-induced Smad2 and Smad3 phosphorylation. Notably, the protein levels of TGIF, a Smad transcriptional co-repressor (62), were significantly suppressed in the CFs in which HGF was knocked down, but increased in the CFs in which HGF was overexpressed following TGF- $\beta_{1}$ stimulation. These findings indicate that in CFs, HGF blocks the TGF- $\beta_{1}$-induced nuclear translocation of phospho-Smad2 and phospho-Smad3, inhibiting CF proliferation, differentiation and secretion. Similarly, HGF suppresses TGF- $\beta_{1}$-mediated renal interstitial myofibroblast activation, and this effect of HGF is likely related to the blockade of Smad nuclear translocation (63).

In conclusion, the results of the present study suggest that HGF exerts its antifibrotic effects on CFs by inhibiting $\mathrm{CF}$ proliferation and transformation. The underlying mechanism is that HGF positively regulates c-Met-Akt-TGIF signaling to inhibit the function of CFs in response to TGF- $\beta_{1}$ stimuli. However, a limitation of this study was that the detailed mechanism by which HGF regulates cardiac fibrosis remains to be elucidated using animal models with TGF- $\beta_{1}$ stimuli. Another limitation was that even though we found that the protein expression of TGIF was significantly affected by HGF, other Smad transcriptional co-repressors, such as c-Ski, Ski-related novel protein $\mathrm{N}(\mathrm{SnoN})$, ecotropic virus integration site 1 protein homolog (Evi1), Smad interacting protein 1 (SIP1) and histone deacetylase (HDAC) 4/5, remain to be explored.

\section{Acknowledgements}

We are grateful to all the members of the Department of Cardiology and the Cardiovascular Research Institute of Renmin Hospital of Wuhan University for providing their technical assistance and advice. This study was supported by grants from the National Natural Science Foundation of China (no. 81170307) and the National Key Basic Research Program of China (no. 2011CB606202).

\section{References}

1. Venugopal JR, Prabhakaran MP, Mukherjee S, et al: Biomaterial strategies for alleviation of myocardial infarction. J R Soc Interface 9: 1-19, 2012.

2. Writing Group Members; Lloyd-Jones D, Adams RJ, Brown TM, et al: American Heart Association Statistics Committee and Stroke Statistics Subcommittee: Heart disease and stroke statistics-2010 update: a report from the American Heart Association. Circulation 121: e46-e215, 2010.

3. Grandi AM, Imperiale D, Santillo R, et al: Aldosterone antagonist improves diastolic function in essential hypertension. Hypertension 40: 647-652, 2002.

4. Zhu JN, Chen R, Fu YH, et al: Smad3 inactivation and MiR-29b upregulation mediate the effect of carvedilol on attenuating the acute myocardium infarction-induced myocardial fibrosis in rat. PLoS One 8: e75557, 2013.

5. Fang L, Beale A, Ellims AH, et al: Associations between fibrocytes and postcontrast myocardial T1 times in hypertrophic cardiomyopathy. J Am Heart Assoc 2: e000270, 2013.

6. Rao AD, Shah RV, Garg R, et al: Aldosterone and myocardial extracellular matrix expansion in type 2 diabetes mellitus. Am J Cardiol 112: 73-78, 2013.

7. Engebretsen KV, Lunde IG, Strand ME, et al: Lumican is increased in experimental and clinical heart failure, and its production by cardiac fibroblasts is induced by mechanical and proinflammatory stimuli. FEBS J 280: 2382-2398, 2013.

8. Ma Y, Halade GV, Zhang J, et al: Matrix metalloproteinase-28 deletion exacerbates cardiac dysfunction and rupture after myocardial infarction in mice by inhibiting M2 macrophage activation. Circ Res 112: 675-688, 2013.

9. Bai J, Zhang N, Hua Y, et al: Metformin inhibits angiotensin II-induced differentiation of cardiac fibroblasts into myofibroblasts. PLoS One 8: e72120, 2013.

10. Lu D, Soleymani S, Madakshire R and Insel PA: ATP released from cardiac fibroblasts via connexin hemichannels activates profibrotic P2Y2 receptors. FASEB J 26: 2580-2591, 2012.

11. Zhang W, Chancey AL, Tzeng HP, et al: The development of myocardial fibrosis in transgenic mice with targeted overexpression of tumor necrosis factor requires mast cell-fibroblast interactions. Circulation 124: 2106-2116, 2011.

12. Kapoun AM, Liang F, O'Young G, et al: B-type natriuretic peptide exerts broad functional opposition to transforming growth factor-beta in primary human cardiac fibroblasts: fibrosis, myofibroblast conversion, proliferation, and inflammation. Circ Res 94: 453-461, 2004.

13. Vilahur G, Juan-Babot O, Peña E, et al: Molecular and cellular mechanisms involved in cardiac remodeling after acute myocardial infarction. J Mol Cell Cardiol 50: 522-533, 2011.

14. He W, Zhang L, Ni A, et al: Exogenously administered secreted frizzled related protein 2 (Sfrp2) reduces fibrosis and improves cardiac function in a rat model of myocardial infarction. Proc Natl Acad Sci USA 107: 21110-21115, 2010.

15. Baum JR, Long B, Cabo C and Duffy HS: Myofibroblasts cause heterogeneous $\mathrm{Cx} 43$ reduction and are unlikely to be coupled to myocytes in the healing canine infarct. Am J Physiol Heart Circ Physiol 302: H790-H800, 2012.

16. Laeremans H,Hackeng TM, van Zandvoort MA, et al: Blocking of frizzled signaling with a homologous peptide fragment of wnt $3 \mathrm{a} /$ wnt5a reduces infarct expansion and prevents the development of heart failure after myocardial infarction. Circulation 124: 1626-1635, 2011.

17. Novoyatleva T, Schymura Y, Janssen W, et al: Deletion of Fn14 receptor protects from right heart fibrosis and dysfunction. Basic Res Cardiol 108: 325, 2013.

18. Lian H, Ma Y, Feng J, et al: Heparin-binding EGF-like growth factor induces heart interstitial fibrosis via an Akt/mTor/p70s6k pathway. PLoS One 7: e44946, 2012.

19. Zhang Y, Wang Y, Liu Y, et al: Krüppel-like factor 4 transcriptionally regulates TGF- $\beta 1$ and contributes to cardiac myofibroblast differentiation. PLoS One 8: e63424, 2013.

20. Zhao T, Zhao W, Chen Y, et al: Platelet-derived growth factor-D promotes fibrogenesis of cardiac fibroblasts. Am J Physiol Heart Circ Physiol 304: H1719-H1726, 2013.

21. Zhu J and Carver W: Effects of interleukin-33 on cardiac fibroblast gene expression and activity. Cytokine 58: 368-379, 2012. 
22. Gazdhar A, Fachinger P, van Leer C, et al: Gene transfer of hepatocyte growth factor by electroporation reduces bleomycin-induced lung fibrosis. Am J Physiol Lung Cell Mol Physiol 292: L529-L536, 2007.

23. Li F, Sun JY, Wang JY, et al: Effect of hepatocyte growth factor encapsulated in targeted liposomes on liver cirrhosis. J Control Release 131: 77-82, 2008

24. Kanemura H, Iimuro Y, Takeuchi M, et al: Hepatocyte growth factor gene transfer with naked plasmid DNA ameliorates dimethylnitrosamine-induced liver fibrosis in rats. Hepatol Res 38: 930-939, 2008.

25. Herrero-Fresneda I, Torras J, Franquesa M, et al: HGF gene therapy attenuates renal allograft scarring by preventing the profibrotic inflammatory-induced mechanisms. Kidney Int 70: 265-274, 2006

26. Okayama K, Azuma J, Dosaka N, et al: Hepatocyte growth factor reduces cardiac fibrosis by inhibiting endothelial-mesenchymal transition. Hypertension 59: 958-965, 2012.

27. Yang ZJ, Chen B, Sheng Z, et al: Improvement of heart function in postinfarct heart failure swine models after hepatocyte growth factor gene transfer: comparison of low-, medium- and high-dose groups. Mol Biol Rep 37: 2075-2081, 2010.

28. Nakamura T, Matsumoto K, Mizuno S, et al: Hepatocyte growth factor prevents tissue fibrosis, remodeling, and dysfunction in cardiomyopathic hamster hearts. Am J Physiol Heart Circ Physiol 288: H2131-H2139, 2005.

29. Takeda S, Liu H, Sasagawa S, et al: HGF-MET signals via the MLL-ETS2 complex in hepatocellular carcinoma. J Clin Invest 123: 3154-3165, 2013.

30. Tsou HK, Chen HT, Hung YH, et al: HGF and c-Met interaction promotes migration in human chondrosarcoma cells. PLoS One 8: e53974, 2013.

31. Ma PC, Tretiakova MS, Nallasura V, et al: Downstream signalling and specific inhibition of c-MET/HGF pathway in small cell lung cancer: implications for tumour invasion. $\mathrm{Br}$ J Cancer 97: 368-377, 2007.

32. Lee WJ, Wu LF, Chen WK, et al: Inhibitory effect of luteolin on hepatocyte growth factor/scatter factor-induced HepG2 cell invasion involving both MAPK/ERKs and PI3K-Akt pathways. Chem Biol Interact 160: 123-133, 2006.

33. Wen X, Li Y, Hu K, et al: Hepatocyte growth factor receptor signaling mediates the anti-fibrotic action of 9-cis-retinoic acid in glomerular mesangial cells. Am J Pathol 167: 947-957, 2005.

34. Huang H, Tang QZ, Wang AB, et al: Tumor suppressor A20 protects against cardiac hypertrophy and fibrosis by blocking transforming growth factor-beta-activated kinase 1-dependent signaling. Hypertension 56: 232-239, 2010.

35. Ai W, Zhang Y, Tang QZ, et al: Silibinin attenuates cardiac hypertrophy and fibrosis through blocking EGFR-dependent signaling. J Cell Biochem 110: 1111-1122, 2010.

36. Yan-Hong F, Hui D, Qing P, et al: Effects of arginine vasopressin on differentiation of cardiac fibroblasts into myofibroblasts. J Cardiovasc Pharmacol 55: 489-495, 2010.

37. Yao J and Eghbali M: Decreased collagen gene expression and absence of fibrosis in thyroid hormone-induced myocardial hypertrophy. Response of cardiac fibroblasts to thyroid hormone in vitro. Circ Res 71: 831-839, 1992.

38. Liu C, Cao F, Tang QZ, et al: Allicin protects against cardiac hypertrophy and fibrosis via attenuating reactive oxygen species-dependent signaling pathways. J Nutr Biochem 21: 1238-1250, 2010

39. Cai J, Yi FF, Bian ZY, et al: Crocetin protects against cardiac hypertrophy by blocking MEK-ERK1/2 signalling pathway. J Cell Mol Med 13: 909-925, 2009.

40. Wang X, Khaidakov M, Ding Z, et al: LOX-1 in the maintenance of cytoskeleton and proliferation in senescent cardiac fibroblasts. J Mol Cell Cardiol 60: 184-190, 2013.

41. Wang K, Zhao X, Kuang C, et al: Overexpression of SDF-1a enhanced migration and engraftment of cardiac stem cells and reduced infarcted size via CXCR4/PI3K pathway. PLoS One 7 e43922, 2012

42. Yang J, Ii M, Kamei N, et al: CD $34^{+}$cells represent highly functional endothelial progenitor cells in murine bone marrow. PLoS One 6: e20219, 2011.
43. Fujita J, Mori M, Kawada H, et al: Administration of granulocyte colony-stimulating factor after myocardial infarction enhances the recruitment of hematopoietic stem cell-derived myofibroblasts and contributes to cardiac repair. Stem Cells 25: 2750-2759, 2007.

44. Adapala RK, Thoppil RJ, Luther DJ, et al: TRPV4 channels mediate cardiac fibroblast differentiation by integrating mechanical and soluble signals. J Mol Cell Cardiol 54: 45-52, 2013.

45. Galie PA, Russell MW, Westfall MV and Stegemann JP Interstitial fluid flow and cyclic strain differentially regulate cardiac fibroblast activation via AT1R and TGF- $\beta 1$. Exp Cell Res 318: 75-84, 2012.

46. Fan YH, Dong H, Pan Q, et al: Notch signaling may negatively regulate neonatal rat cardiac fibroblast-myofibroblast transformation. Physiol Res 60: 739-748, 2011.

47. Melchior-Becker A, Dai G, Ding Z, et al: Deficiency of biglycan causes cardiac fibroblasts to differentiate into a myofibroblast phenotype. J Biol Chem 286: 17365-17375, 2011.

48. Kumar S and Gupta S: Thymosin beta 4 prevents oxidative stress by targeting antioxidant and anti-apoptotic genes in cardiac fibroblasts. PLoS One 6: e26912, 2011.

49. Dai B, Cui M, Zhu M, et al: STAT1/3 and ERK1/2 synergistically regulate cardiac fibrosis induced by high glucose. Cell Physiol Biochem 32: 960- 971, 2013.

50. Cao Y, Xu W and Xiong S: Adoptive transfer of regulatory $\mathrm{T}$ cells protects against coxsackievirus B3-induced cardiac fibrosis. PLoS One 8: e74955, 2013.

51. Kazakov A, Hall R, Jagoda P, et al: Inhibition of endothelial nitric oxide synthase induces and enhances myocardial fibrosis. Cardiovasc Res 100: 211-221, 2013.

52. Hou X, Zhang Y, Shen YH, et al: PPAR- $\gamma$ activation by rosiglitazone suppresses angiotensin II-mediated proliferation and phenotypictransition in cardiac fibroblasts via inhibition of activation of activator protein 1. Eur J Pharmacol 715: 196-203, 2013.

53. Sirish P, Li N, Liu JY, et al: Unique mechanistic insights into the beneficial effects of soluble epoxide hydrolase inhibitors in the prevention of cardiac fibrosis. Proc Natl Acad Sci USA 110: 5618-5623, 2013

54. González A, Ravassa S, Beaumont J, López B and Díez J: New targets to treat the structural remodeling of the myocardium. J Am Coll Cardiol 58: 1833-1843, 2011.

55. Campbell SE, Janicki JS and Weber KT: Temporal differences in fibroblast proliferation and phenotype expression in response to chronic administration of angiotensin II or aldosterone. J Mol Cell Cardiol 27: 1545-1560, 1995

56. Porter KE and Turner NA: Cardiac fibroblasts: at the heart of myocardial remodeling. Pharmacol Ther 123: 255-278, 2009.

57. Burstein B, Libby E, Calderone A and Nattel S: Differential behaviors of atrial versus ventricular fibroblasts: a potential role for platelet-derived growth factor in atrial-ventricular remodeling differences. Circulation 117: 1630-1641, 2008.

58. Weber KT, Sun Y, Bhattacharya SK, Ahokas RA and Gerling IC: Myofibroblast-mediated mechanisms of pathological remodelling of the heart. Nat Rev Cardiol 10: 15-26, 2013.

59. Salimath AS, Phelps EA, Boopathy AV, et al: Dual delivery of hepatocyte and vascular endothelial growth factors via a protease-degradable hydrogel improves cardiac function in rats. PLoS One 7: e50980, 2012.

60. Lu F, Zhao X, Wu J, et al: MSCs transfected with hepatocyte growth factor or vascular endothelial growth factor improve cardiac function in the infarcted porcine heart by increasing angiogenesis and reducing fibrosis. Int J Cardiol 167: 2524-2532, 2013.

61. Guo YH, He JG, Wu JL, et al: Hepatocyte growth factor and granulocyte colony-stimulating factor form a combined neovasculogenic therapy for ischemic cardiomyopathy. Cytotherapy 10: 857-867, 2008

62. Lo RS, Wotton D and Massagué J: Epidermal growth factor signaling via Ras controls the Smad transcriptional co-repressor TGIF. EMBO J 20: 128-136, 2001.

63. Yang J, Dai C and Liu Y: Hepatocyte growth factor suppresses renal interstitial myofibroblast activation and intercepts Smad signal transduction. Am J Pathol 163: 621-632, 2003. 